\title{
TEORES DE VANÁDIO, MOLIBDÊNIO E ANTIMÔNIO EM SOLOS DE DIFERENTES LITOLOGIAS EM SANTA CATARINA
}

\author{
Ilana Marin Suppia ${ }^{a * \odot}$, , Mari Lucia Campos ${ }^{\mathrm{a}}$, David Jose Miquellutia ${ }^{\mathrm{a}}$ Matheus Rodrigo Machado ${ }^{\mathrm{a}}$ \\ ${ }^{a}$ Departamento de Solos e Recursos Naturais, Centro de Ciências Agroveterinárias, Universidade do Estado de Santa Catarina, \\ 88520-000 Lages - SC, Brasil
}

Recebido em 01/02/2021; aceito em 22/04/2021; publicado na web em 19/05/2021

\begin{abstract}
VANADIUM, MOLYBDENUM AND ANTIMONY CONTENTS IN SOILS OF DIFFERENT LITHOLOGIES IN SANTA CATARINA. Trace element levels knowledge in soils is important for establishing quality standards. This study has objective to determine levels of vanadium (V), molybdenum (Mo) and antimony ( $\mathrm{Sb}$ ) in soils from Santa Catarina, observing the different source materials and establishing relationships between these elements and soil properties. The extractions occurred according to USEPA 3051 A protocol, with nitric and hydrochloric acid addition for $\mathrm{V}$ and Mo and only with hydrochloric acid for Sb. The quantification of $\mathrm{V}$ and Mo occurred by inductively coupled plasma optical emission spectrometry and of Sb by hydride generation inductively coupled plasma optical emission spectrometry. The results were submitted to variance analysis and Scott-Knott test and evaluated by Pearson's correlation with soil attributes. V and Mo contents differed between soils of different source materials. Highest V levels were found in andesite and basalt soils and Mo in porphyry phonolite, granite, mica schist and sedimentary rocks. V and Sb showed a positive correlation with each other and with oxides of iron, silt, and organic carbon. Mo showed a negative correlation with cation exchange capacity (CEC), iron oxides and organic carbon.
\end{abstract}

Keywords: trace elements; natural contents; source material.

\section{INTRODUÇÃo}

Com o elevado crescimento demográfico mundial, cada vez mais tem aumentado a quantidade de indústrias para atendimento às demandas da população. Essas indústrias acabam gerando resíduos, muitas vezes descartados irregularmente na natureza. Esses resíduos podem conter quantidades significativas de elementos-traço, os quais podem acarretar danos à saúde humana e aos ecossistemas. Dessa forma, a contaminação do meio-ambiente por esses elementos tem-se tornado foco de estudos em todo o mundo.

Os solos são de extrema importância no meio ambiente, pois atuam como filtro, controlando o transporte de elementos-traço para corpos d'água, por exemplo. Porém essa capacidade tampão é limitada, podendo assim os solos se tornarem fontes de contaminantes para outros compartimentos. Portanto, é essencial conhecer a composição dos solos e compreender os processos que ocorrem neles. ${ }^{2}$

Elementos-traço (ET) são elementos químicos presentes nos solos em concentrações menores que $1000 \mathrm{mg} \mathrm{kg}^{-1} \cdot{ }^{3}$ Diferenças na composição geoquímica dos materiais de origem do solo, bem como as variações na intensidade dos processos de formação podem resultar em amplas faixas de concentração de elementos-traço nos solos, mesmo naqueles não afetados pela contaminação. ${ }^{4}$ Ressalta-se que mesmo em condições rigorosas de intemperismo, a rocha mãe ainda exerce grande influência no conteúdo de elementos-traço no solo. ${ }^{5}$ Já como fontes antropogênicas pode-se citar a mineração, atividades industriais, emissões de tráfego, uso de pesticidas e fertilizantes químicos. ${ }^{6}$

A determinação dos teores de elementos-traço em condições naturais é fundamental para o estabelecimento de padrões de qualidade do solo. Esses valores podem servir como ferramentas legislativas no desenvolvimento de valores orientadores para prevenção, controle e remediação da poluição do solo. ${ }^{7}$

Desta forma, com a necessidade de proteger esse recurso, o Conselho Nacional de Meio Ambiente (CONAMA) homologou a

*e-mail: ilanalgs@yahoo.com.br
Resolução $\mathrm{n}^{\circ} 420^{8}$ que estabelece valores orientadores para solo e águas subterrâneas e determina que os órgãos ambientais competentes dos Estados e do Distrito Federal estabeleçam os Valores de Referência de Qualidade (VRQ) de vinte substâncias inorgânicas presentes naturalmente nos solos, em virtude de suas particularidades geológicas, geomorfológicas e pedológicas. Os VRQ são baseados na avaliação dos teores naturais dos elementos nos solos, ou seja, a concentração de determinada substância que define a qualidade natural do solo. ${ }^{8}$

O ideal é ter um banco de solos de referência coletados em local de ausência, quando possível, ou de mínima atividade antrópica. ${ }^{2}$ Porém quase toda a superfície terrestre foi influenciada por atividades humanas, por isso termo concentração de base (background), que é a concentração encontrada em um determinado tempo, durante um estudo ou trabalho, é o mais correto a se utilizar, ${ }^{9,10}$ considerando assim o tempo da amostragem como tempo zero para fins de monitoramento, pois o aumento no teor total do elemento após a determinação da concentração de base será antropogênico. ${ }^{11}$

Das vinte substâncias elencadas na Resolução do CONAMA ${ }^{8}$, já foram determinados os teores naturais de nove: cobre, zinco, ${ }^{12} \mathrm{cromo}$, chumbo, ${ }^{11}$ níquel, bário, cádmio, ${ }^{13}$ cobalto e manganês. ${ }^{14}$ Dentre os elementos que precisam ter seus teores naturais determinados, estão vanádio (V), molibdênio (Mo) e antimônio (Sb) que em teores elevados nos solos podem ocasionar danos aos seres vivos.

No estado de Santa Catarina, localizado na região sul do Brasil afloram rochas como migmatitos, granulitos do Arqueano; granitóides, rochas metassedimentares e metamórficas de idade proterozóica; rochas sedimentares gondwânicas paleozóicas da Bacia do Paraná; rochas basálticas, intermediárias e ácidas mesozóicas representadas pelo Planalto da Serra Geral; rochas alcalinas do final do Mesozóico e início do Terciário e os sedimentos de idade cenozóica que compreendem a Planície Costeira. ${ }^{15}$ Dessa forma, a variabilidade de material de origem e consequentemente de solos no do estado é muito grande, sendo que para um estudo de variabilidade na composição de elementos-traço em solos, se faz 
necessário a análise de diferentes amostras, advindas de diferentes tipos de solos.

$O$ vanádio pode ocorrer na natureza em pelo menos seis estados de oxidação sendo os estados 3+, 4+ e 5+ os mais comuns. Em minerais do solo, o vanádio é encontrado nos estados de oxidação tetravalente (4+) e trivalente $(3+) .{ }^{16} \mathrm{O} \mathrm{V}^{5+}$ é considerado mais tóxico para humanos, pois pode afetar a atividade de enzimas específicas e também atuar como um inibidor dos equilíbrios de sódio/potássio e cálcio/magnésio no organismo, sendo considerado um poluente perigoso. ${ }^{16}$ Embora o vanádio seja essencial para os organismos vivos, quantidades excessivas no corpo humano podem causar problemas de saúde, inclusive estudos têm explorado o potencial carcinogênico do vanádio, porém sem evidências conclusivas. ${ }^{17}$

$\mathrm{O}$ antimônio é normalmente encontrado em quatro estados de oxidação sendo as formas $3+$ e $5+$ as mais comuns. ${ }^{18}$ Em ambientes com oxigênio, o $\mathrm{Sb}^{5+}$ é mais estável que o $\mathrm{Sb}^{3+}$. $\mathrm{O} \mathrm{Sb}^{+3}$ associado à matéria orgânica e ácidos húmicos é facilmente oxidado por fotooxidantes como o peróxido de hidrogênio. ${ }^{19} \mathrm{O} \mathrm{Sb}$ está presente na natureza em diferentes formas físico-químicas e a sua toxicidade é dependente da forma que ele se encontra disponível no meio de estudo. Os organoantimoniais, por exemplo, são menos tóxicos que o $\mathrm{Sb}^{5+}$, que por sua vez é menos tóxico que o $\mathrm{Sb}^{3+} \cdot{ }^{20} \mathrm{~A}$ ingestão excessiva de antimônio por humanos pode resultar em efeitos gastrointestinais, alterações hematológicas e alterações histológicas na tireoide. ${ }^{21}$

O molibdênio pode ocorrer em 5 estados de oxidação, sendo os predominantes na natureza 4+ e 6+. Em seu estado tetravalente, o molibdênio é insolúvel em fluidos aquosos, mas quando oxidado em seu estado hexavalente torna-se solúvel. ${ }^{22} \mathrm{O}$ Mo é um elemento essencial para os seres vivos e a principal forma de exposição humana dos animais a ele é através dos alimentos. ${ }^{23} \mathrm{~A}$ função do molibdênio em animais ruminantes está intimamente relacionada às reações de interação com cobre e enxofre, sendo que qualquer aumento da quantidade ideal de molibdênio, pode acarretar deficiência de cobre, uma vez que ambos são antagonistas biológicos. ${ }^{24}$

Devido ao grande desenvolvimento agrícola e industrial de Santa Catarina, a determinação dos teores naturais de elementos-traço é extremamente importante para a o uso análises de risco, em projetos antes da emissão de licenças ambientais, identificação e proteção de populações que moram próximas a empreendimento industriais e minerários e a criação de um inventário de áreas contaminadas.

Sendo assim, o objetivo desse estudo foi determinar os teores naturais dos elementos-traço vanádio $(\mathrm{V})$, molibdênio (Mo) e antimônio ( $\mathrm{Sb}$ ) em solos de diferentes materiais de origem no estado de Santa Catarina, a fim de contribuir com o monitoramento dos elementos, bem como estabelecer relações entre esses e propriedades físicas e químicas dos solos.

\section{PARTE EXPERIMENTAL}

Para esta pesquisa, foram utilizadas amostras do banco de solos da Universidade do Estado de Santa Catarina, oriundas do horizonte A (profundidade de $0-20 \mathrm{~cm}$ ) de 54 perfis de solos representativos do estado, coletados em áreas não sujeitas à contaminação antropogênica (Figura 1 e Tabela 1). Os perfis de solo já haviam sido previamente coletados, descritos e classificados. ${ }^{25-33}$ As amostras de solo foram moídas em gral de ágata e tamisadas em peneira de $0,053 \mathrm{~mm}$, a fração de solo utilizada para este trabalho foi a que passou pela peneira, inclusive toda a amostra de solo retirada do banco de solos foi moída e passada pela peneira.

Para determinação de $\mathrm{V}$ e Mo, foi transferido para tubos de teflon $0,2500 \mathrm{~g}$ de solo, ao qual foram adicionados, com o uso de uma pipeta automática, primeiramente $4,5 \mathrm{~mL}$ de ácido nítrico $\left(\mathrm{HNO}_{3}\right) 65 \%$ P.A em todas as amostras e, logo em seguida, $1,5 \mathrm{~mL}$ de ácido clorídrico ( $\mathrm{HCl}$ ) 37\% P.A. As amostras de solo ficaram em contato com o ácido por 12 horas. Após isso, a digestão ocorreu em forno de micro-ondas Anton PAAR Multiwave 3000® (método USEPA 3051A) descrito pela United States Environnmental Protection Agency. ${ }^{34}$ Os extratos foram filtrados, usando-se papel filtro quantitativo (faixa azul) e armazenados em tubos Falcon. A quantificação dos elementos foi por espectrometria de emissão ótica com fonte de plasma acoplado indutivamente (ICP OES), modelo Optima 8300®, Perkin Elmer.

Para determinação de $\mathrm{Sb}$ foram utilizados 33 perfis de solos (1-3, 5-8, 10-12, 14, 18, 19, 22, 29-31, 35, 39-51, 53, 54). Foi transferido $1,5000 \mathrm{~g}$ de solo para tubos de teflon e acrescentados, com o uso de uma pipeta automática, $5 \mathrm{~mL}$ de $\mathrm{HCl} 37 \%$ P.A. As amostras ficaram em contato com o ácido por 12 horas, então foram submetidas à digestão em forno de micro-ondas Anton PAAR Multiwave 3000 (método USEPA 3051A). ${ }^{34}$ Após a digestão, as amostras foram transferidas para tubos Falcon que foram colocados em centrífuga Fanem $^{\circledR}$, modelo 206 BL, a 3000 rpm por 3 minutos, a fim de separar as fases sólida e líquida. A fase líquida foi então transferida para um balão volumétrico de $10 \mathrm{~mL}$ e procedeu-se com uma etapa de préredução do $\mathrm{Sb}(\mathrm{V})$ para $\mathrm{Sb}(\mathrm{III})$, adicionando-se a todas as amostras $0,45 \mathrm{~mL}$ de uma solução de iodeto de potássio a $5 \% \mathrm{~m} / \mathrm{v}$ e ácido ascórbico a $5 \% \mathrm{~m} / \mathrm{v}$ na solução de leitura de $10 \mathrm{~mL}$, então as amostras ficaram em repouso por 12 horas. Após, houve a quantificação de Sb por espectrometria de emissão óptica por plasma acoplado indutivamente com geração de hidretos (ICP OES HG) a vapor frio, modelo Optima 8300 da marca Perkin Elmer.

As condições do forno de micro-ondas para a digestão de todas as amostras de solo desse trabalho estão expressas na Tabela 2.

As análises estatísticas foram conduzidas utilizando-se o software R. ${ }^{35}$ Os resultados foram submetidos aos testes $\mathrm{F}$ e de Scott-Knott, a partir da transformação logarítmica dos valores de V, Mo e Sb, a fim de comparar os materiais de origem, para isso, utilizouse o valor médio de cada elemento estudado para cada material de origem de solos. Para todos os testes, foi considerado o nível mínimo de $5 \%$ de significância. Os teores de V, Mo e Sb encontrados também foram avaliados pela correlação de Pearson, utilizando-se as variáveis argila, silte, carbono orgânico $(\mathrm{CO})$, capacidade de troca catiônica (CTC) e óxidos de ferro (Fe). Tais variáveis haviam anteriormente sido determinadas por Almeida et al. $;{ }^{25}$ Correa $;{ }^{26}$ Almeida et al.,${ }^{27}$ Paes Sobrinho et al. $;{ }^{28}$ Bringhenti et al. $;{ }^{29}$ Costa et al. $;{ }^{30}$ Ferreira $;{ }^{31}$ Lunardi Neto e Almeida; ${ }^{32}$ Teske et $a l .{ }^{33}$ e seus valores são apresentados na Tabela 3 .

\section{RESULTADOS E DISCUSSÃO}

Em todas as baterias de digestão foi incluída uma amostra certificada NIST 2709A (SRM San Joaquin Soil) e provas em branco. O Limite de Detecção (LD) foi calculado segundo a equação $\mathrm{LD}=(\mathrm{M} \pm \mathrm{t} * \mathrm{~s}),{ }^{36}$ onde $M$ é a média das provas em branco, $t$ é o valor t-Student para intervalo de confiança de $99 \%$, em função do número de graus de liberdade de medições repetidas e $s$ é o desvio padrão das provas em branco. O Limite de Quantificação (LQ) foi obtido multiplicando o LD por 3. As taxas de recuperação da amostra certificada e os LD são apresentados na Tabela 4. Os teores certificados dos elementos-traço na amostra referência são os teores totais, obtidos através de digestão utilizando ácido fluorídrico, extraindo assim os elementos que estão nas estruturas dos silicatos. Já para este trabalho foram utilizadas metodologias de digestão "pseudo-totais", que são sugeridas pela resolução do CONAMA $420^{8}$ e refletem com maior aproximação a disponibilidade ambiental dos elementos-traço. O certificado da amostra referência traz ainda uma tabela com uma faixa de teores médios dos elementos obtidos por 
Tabela 1. Identificação, classe de solo, material de origem, município de amostragem e coordenadas geográficas (geodésicas decimais) dos perfis de solos estudados neste trabalho

\begin{tabular}{|c|c|c|c|c|c|}
\hline Perfil & Classe de Solo & Material de Origem & Município & Latitude & Longitude \\
\hline 1 & Argissolo Amarelo Alítico típico & Micaxisto & Botuverá & $-27,190$ & $-49,064$ \\
\hline 2 & Argissolo Amarelo Distrófico latossólico & Migmatito & São Bonifácio & $-27,939$ & $-48,937$ \\
\hline 3 & Argissolo Amarelo Distrófico típico & Granito e Granulito & Rancho Queimado & $-27,697$ & $-49,047$ \\
\hline 4 & Argissolo Amarelo Distrófico típico & Horblendito & Pomerode & $-26,738$ & $-49,228$ \\
\hline 5 & Argissolo Bruno-Acinzentado Alítico típico & Argilito e Siltito & Alfredo Wagner & $-27,668$ & $-49,187$ \\
\hline 6 & Argissolo Vermelho distrófico & Siltito e Arenito & Içara & $-28,724$ & $-49,289$ \\
\hline 7 & Argissolo Vermelho Distrófico abrúptico & Siltito e Arenito & Içara & $-28,727$ & $-49,295$ \\
\hline 8 & Argissolo Vermelho Distrófico abruptico & Siltito e Arenito & Içara & $-28,727$ & $-49,295$ \\
\hline 9 & Argissolo Vermelho-Amarelo Alítico típico & Granulito Máfico & Luiz Alves & $-26,682$ & $-49,009$ \\
\hline 10 & Argissolo Vermelho-Amarelo Alumínico típico & Metaarenito & Gaspar & $-26,994$ & $-48,903$ \\
\hline 11 & Argissolo Vermelho-Amarelo Alumínico típico & Granulito Máfico & Blumenau & $-26,798$ & $-49,089$ \\
\hline 12 & Argissolo Vermelho-Amarelo Distrófico latossólico & Arenito e Siltito & Lauro Müller & $-28,390$ & $-49,368$ \\
\hline 13 & Argissolo Vermelho-Amarelo Distrófico latossólico & Migmatito & Águas Mornas & $-27,722$ & $-48,936$ \\
\hline 14 & Argissolo Vermelho-Amarelo Distrófico latossólico & Arenito e Siltito & Lauro Müller & $-28,390$ & $-49,368$ \\
\hline 15 & Argissolo Vermelho-Amarelo Distrófico típico & Granito & Treze de Maio & $-28,617$ & $-49,131$ \\
\hline 16 & Cambissolo Háplico Alítico típico & Riodacito & Lages & $-28,268$ & $-50,395$ \\
\hline 17 & Cambissolo Háplico Alítico típico & Riodacito & Lages & $-28,395$ & $-50,177$ \\
\hline 18 & Cambissolo Háplico Alítico típico & Riodacito & Lages & $-28,411$ & $-50,174$ \\
\hline 19 & Cambissolo Háplico Alumínico típico & Fonolito Porfirítico & Palmeira & $-27,564$ & $-50,240$ \\
\hline 20 & Cambissolo Háplico Alumínico úmbrico & Fonolito & Lages & $-27,779$ & $-50,232$ \\
\hline 21 & Cambissolo Háplico Alumínico úmbrico & Riodacito & Lages & $-27,930$ & $-50,273$ \\
\hline 22 & Cambissolo Háplico Alumínico úmbrico & Riodacito & Lages & $-28,311$ & $-50,396$ \\
\hline 23 & Cambissolo Háplico Eutroférrico típico & Basalto & Descanso & $-27,396$ & $-51,806$ \\
\hline 24 & Cambissolo Háplico Ta Eutrófico típico & Basalto & Luzerna & $-27,091$ & $-51,489$ \\
\hline 25 & Cambissolo Háplico Tb Distrófico típico & Granito & Treze de Maio & $-28,567$ & $-49,117$ \\
\hline 26 & Cambissolo hístico & Siltito & Otacílio Costa & $-27,815$ & $-49,544$ \\
\hline 27 & Cambissolo Húmico Alumínico típico & Sienito Porfirítico & Lages & $-27,644$ & $-50,164$ \\
\hline 28 & Cambissolo Húmico Distróférrico típico & Basalto & Lages & $-27,794$ & $-50,403$ \\
\hline 29 & Cambissolo Húmico Distrófico típico & Riodacito & Lages & $-28,331$ & $-50,303$ \\
\hline 30 & Chernossolo Argilúvico Férrico típico & Basalto & Descanso & $-26,863$ & $-53,480$ \\
\hline 31 & Chernossolo Argilúvico Férrico típico & Basalto & Ipira & $-27,396$ & $-51,806$ \\
\hline 32 & Chernossolo Háplico Férrico típico & Basalto & Descanso & $-26,863$ & $-53,489$ \\
\hline 33 & Chernossolo Háplico Órtico típico & olivina melilitito & Palmeira & $-27,161$ & $-50,092$ \\
\hline 34 & Latossolo Vermelho Distroférrico húmico & Basalto & Faxinal dos Guedes & $-26,811$ & $-52,306$ \\
\hline 35 & Latossolo Vermelho Distrófico retrático úmbrico & Basalto & Campos Novos & $-27,375$ & $-51,085$ \\
\hline 36 & Latossolo Vermelho Distrófico retrático úmbrico & Basalto & Campos Novos & $-27,376$ & $-51,091$ \\
\hline 37 & Neossolo Litólico Álico húmico & riodacito & São Joaquim & $-28,233$ & $-49,833$ \\
\hline 38 & Neossolo Litólico Eutrófico chernossólico & Basalto & Ipira & $-27,386$ & $-51,799$ \\
\hline 39 & Neossolo Quartzarênico Órtico típico & sedimentos arenosos & Imbituba & $-28,220$ & $-48,696$ \\
\hline 40 & Neossolo Quartzarênico Órtico típico & sedimentos arenosos & Araranguá & $-29,005$ & $-49,518$ \\
\hline 41 & Neossolo Regolítico Eutrófico típico & Granito & Sangão & $-28,617$ & $-49,131$ \\
\hline 42 & Neossolo Regolítico Húmico típico & Fonolito & Lages & $-27,779$ & $-50,232$ \\
\hline 43 & Nitossolo Bruno Distroférrico típico & Andesito Basalto & Água Doce & $-26,691$ & $-51,566$ \\
\hline 44 & Nitossolo Bruno Distrófico húmico latossólico rúbrico & Riodacito & Ponte Serrada & $-26,856$ & $-52,042$ \\
\hline 45 & Nitossolo Bruno Distrófico húmico latossólico rúbrico & Basalto & Curitibanos & $-27,370$ & $-50,579$ \\
\hline 46 & Nitossolo Bruno Distrófico rúbrico & Basalto & Lebon Régis & $-26,947$ & $-50,706$ \\
\hline 47 & Nitossolo Bruno Distrófico típico & Basalto & Painel & $-27,895$ & $-50,129$ \\
\hline 48 & Nitossolo Háplico Distrófico típico & riodacito & Luzerna & $-27,044$ & $-51,537$ \\
\hline 49 & Nitossolo Háplico Distrófico típico & Basalto & Luzerna & $-27,079$ & $-51,502$ \\
\hline 50 & Nitossolo Vermelho Alítico típico & Basalto & Lages & $-28,376$ & $-50,286$ \\
\hline 51 & Nitossolo Vermelho Distroférrico típico & Basalto & Lages & $-28,345$ & $-50,294$ \\
\hline 52 & Nitossolo Vermelho Eutroférrico chernossólico & Basalto & Descanso & $-26,860$ & $-53,496$ \\
\hline 53 & Nitossolo Vermelho Eutroférrico típico & Basalto & Ipira & $-27,378$ & $-51,830$ \\
\hline 54 & Nitossolo Vermelho Eutrófico típico & Basalto & Luzerna & $-27,112$ & $-51,478$ \\
\hline
\end{tabular}




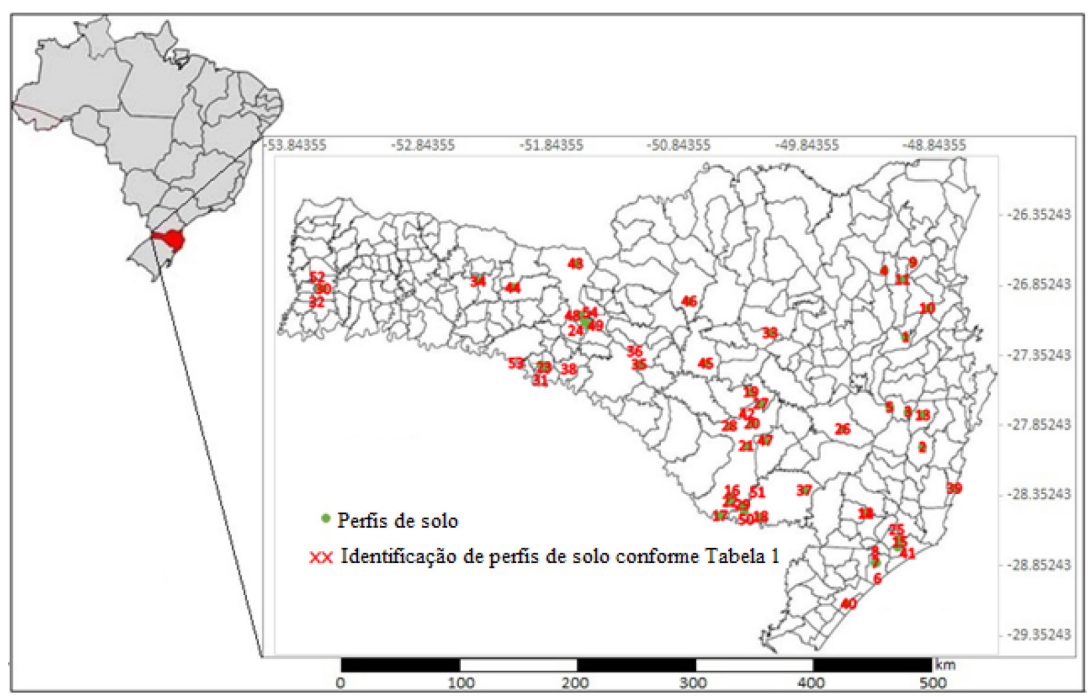

Figura 1. Mapa do estado de Santa Catarina, sua localização no Brasil e localização dos perfis de solo amostrados

Tabela 2. Condições do forno de micro-ondas para digestão das amostras

\begin{tabular}{ccc}
\hline Potência $(\mathrm{W})$ & Rampa $(\min )$ & Espera $(\mathrm{min})$ \\
\hline 500 & $02: 30$ & $10: 00$ \\
800 & $02: 30$ & $05: 00$ \\
Zero & $00: 00$ & $10: 00$ \\
\hline
\end{tabular}

laboratórios utilizando metodologias de digestão "pseudo-total" e análise em ICP, o que também é apresentado na Tabela 4.

Ao analisar os teores obtidos nesse trabalho, notou-se que houve diferença significativa para os teores de $\mathrm{V}$ e Mo entre materiais de origem, o que não foi observado para os teores de $\mathrm{Sb}$.

Em relação ao material de origem, houve a formação de 3 grupos $(\mathrm{A}, \mathrm{B}, \mathrm{C})$ para o elemento vanádio, em que solos de mesmo agrupamento não tiveram diferenças estatísticas entre seus teores médios. Os solos do grupo A (Tabela 5) apresentaram os maiores teores de vanádio. Esses solos possuem como material de origem andesito basalto e basalto.

$\mathrm{OV}^{3+}$ possui raio iônico $0,065 \mathrm{~nm}$ e tem semelhança geoquímica com o $\mathrm{Fe}^{3+}$, que possui raio iônico $0,067 \mathrm{~nm}$, o que permite a substituição em minerais primários e secundários. ${ }^{37,38}$ Como o vanádio facilmente substitui o ferro nos minerais, é mais abundante em rochas máficas que em félsicas. ${ }^{39} \mathrm{O}$ basalto é composto principalmente de minerais de silicato máfico primário, incluindo feldspato, piroxênio, olivina, hornblenda e biotita, esses minerais geralmente têm elevado teor de elementos de transição, como o vanádio. ${ }^{40}$

O grupo B, que apresenta teores intermediários, engloba solos originados de riodacito e olivina melitito, os demais solos ficaram no grupo C. Ainda no grupo $\mathrm{C}$, as menores concentrações de V foram encontradas em solos oriundos de sedimentos arenosos, que são materiais com predominância da fração areia, ou seja, têm menor eficiência na adsorção de metais pesados, devido ao menor número de sítios de ligação e consequentemente serão mais pobres em V.4 ${ }^{41}$

Os teores médios de $\mathrm{V}\left(350,06 \mathrm{mg} \mathrm{kg}^{-1}\right)$ encontrados nos Latossolos catarinenses foram superiores aos encontrados por Paye et al..$^{42}$ em Latossolos do Espírito Santo $(102,25)$. Em relação aos Argissolos, os teores de $\mathrm{V}$ em solos de SC $\left(31,50 \mathrm{mg} \mathrm{kg}^{-1}\right)$ foram menores que em solos do ES $\left(90,10 \mathrm{mg} \mathrm{kg}^{-1}\right)$. Já os teores médios e máximos de V em solos de SC (201,80 e 690,20 mg kg-1) foram bastante superiores aos teores médios em máximos em solos do RN $\left(22,39 \text { e } 183,94 \mathrm{mg} \mathrm{kg}^{-1}\right)^{41}$ e da planície litorânea do Paraná $(37,12$ e
261,75 $\left.\mathrm{mg} \mathrm{kg}^{-1}\right) .^{43}$ Os teores de vanádio superiores em solos de SC refletem a grande quantidade de solos de origem basáltica no estado. Já os Argissolos, que apresentaram menores teores de V, são solos que apresentam, em sua maioria, material de origem com baixos teores de Fe.

Quanto ao molibdênio, analisando os diferentes materiais de origem dos solos, houve a formação de 2 grupos (A, B) (Tabela 6), em que solos de mesmo agrupamento não tiveram diferenças estatísticas entre seus teores médios.

Os maiores teores de Mo encontrados neste trabalho foram em solos derivados de fonolito porfírio, granito, micaxisto e rochas sedimentares. Como visto, a presença de molibdênio nos solos também está relacionada ao seu material de origem. O Mo está presente na crosta terrestre em pequena quantidade, ${ }^{44}$ porém se concentra principalmente em rochas sedimentares e em magmáticas félsicas, ${ }^{37}$ já que a fonte magmática de molibdênio é bastante ácida, ou seja, está presente em magmas ricos em sílica e pobres em ferro e magnésio. ${ }^{44}$

Os teores médios e máximos de Mo em solos de Santa Catarina (2,19 e 5,36 $\left.\mathrm{mg} \mathrm{kg}^{-1}\right)$ foram superiores aos teores médios e máximos em solos da Paraíba $\left(0,1 \text { e } 0,43 \mathrm{mg} \mathrm{kg}^{-1}\right)^{45}$ e da Amazônia Central $\left(0,06\right.$ e $\left.0,49 \mathrm{mg} \mathrm{kg}^{-1}\right) .^{7} \mathrm{O}$ molibdênio está presente nos solos em baixas quantidades, variando entre 0,1 e $7 \mathrm{mg} \mathrm{kg}^{-1} .^{24}$

Já os teores de antimônio nos solos de diferentes materiais de origem não apresentaram diferenças significativas. Além disso nota-se que os teores de antimônio nos solos de Santa Catarina são bastante baixos (Tabela 7).

O antimônio está presente na natureza em baixas quantidades nos diferentes tipos de rochas e minerais, o que refletiu nos baixos teores do elemento nos solos analisados. ${ }^{18}$

Os teores médios de $\mathrm{Sb}$ em SC $\left(0,37 \mathrm{mg} \mathrm{kg}^{-1}\right)$ foram semelhantes aos teores encontrados na PB $\left(0,42 \mathrm{mg} \mathrm{kg}^{-1}\right)^{45}$ e menores que os de Fernando de Noronha $\left(4,60 \mathrm{mg} \mathrm{kg}^{-1}\right),{ }^{46}$ esses teores altos em Fernando de Noronha ocorrem pela presença de rochas ultramáficas e ankaratritos, o que não acontece em SC.

A variação observada teores naturais de $\mathrm{V}$, Mo e $\mathrm{Sb}$ em relação aos em outras regiões do Brasil está relacionada principalmente à diversidade dos materiais de origem, mas também com as características climáticas e processos de formação dos solos. Diante disso, confirma-se que é necessário a determinação de elementos-traço para as diferentes regiões, a fim de orientar corretamente os órgãos ambientais.

Parâmetros físicos e químicos como teor de argila, conteúdo de matéria orgânica e óxidos de Fe contribuem para a variabilidade 
Tabela 3. Atributos físicos e químicos dos 54 perfis de solos estudados

\begin{tabular}{|c|c|c|c|c|c|}
\hline \multirow[t]{2}{*}{ Perfil } & $\begin{array}{c}\text { Teor de } \\
\text { Silte }\end{array}$ & $\begin{array}{l}\text { Teor de } \\
\text { Argila }\end{array}$ & $\mathrm{CO}$ & $\begin{array}{c}\text { Óxidos de } \\
\text { Fe }\end{array}$ & \multirow{2}{*}{$\begin{array}{c}\mathrm{CTC} \\
\mathrm{cmol}_{\mathrm{c}} \mathrm{kg}^{-}\end{array}$} \\
\hline & \multicolumn{4}{|c|}{ - } & \\
\hline 1 & 240 & 230 & 21,7 & 12,6582 & 15,65 \\
\hline 2 & 320 & 370 & 33 & 23,791 & 8,97 \\
\hline 3 & 440 & 330 & 35,3 & 25,3035 & 11 \\
\hline 4 & 210 & 260 & 28,4 & 27,0725 & 9,61 \\
\hline 5 & 520 & 320 & 30,2 & 15,8348 & 21,3 \\
\hline 6 & 140 & 180 & 17 & 13,0195 & 6,21 \\
\hline 7 & 368 & 170 & 14,6 & 13,75 & 6,2 \\
\hline 8 & 368 & 170 & 14,6 & 16,9231 & 6,2 \\
\hline 9 & 220 & 360 & 30 & 27,1731 & 15,89 \\
\hline 10 & 110 & 380 & 27 & 10,3905 & 14,5 \\
\hline 11 & 180 & 240 & 24,9 & 14,5192 & 15,07 \\
\hline 12 & 126 & 157 & 12,8 & 11,4177 & 5,8 \\
\hline 13 & 180 & 450 & 21 & 20,3858 & 6,65 \\
\hline 14 & 80 & 300 & 20 & 12,3326 & 5,8 \\
\hline 15 & 80 & 300 & 9 & 17,9766 & 2,68 \\
\hline 16 & 260 & 640 & 33 & 46,1099 & 25,5 \\
\hline 17 & 328,8 & 610 & 32,7 & 44,2932 & 26,3 \\
\hline 18 & 330,8 & 570 & 33 & 39,1443 & 23,4 \\
\hline 19 & 240 & 500 & 20,8 & 50,3707 & 12,4 \\
\hline 20 & 240 & 550 & 22,2 & 22,9254 & 13,2 \\
\hline 21 & 240 & 620 & 43,3 & 91,6875 & 19,6 \\
\hline 22 & 360 & 580 & 33,7 & 41,2389 & 23,9 \\
\hline 23 & 230 & 500 & 40,7 & 113,637 & 15,34 \\
\hline 24 & 190 & 480 & 34,3 & 104,119 & 14,28 \\
\hline 25 & 170 & 300 & 14 & 10,7012 & 5,71 \\
\hline 26 & 207 & 481 & 33 & 37,9762 & 22,12 \\
\hline 27 & 360 & 460 & 39 & 38,9703 & 17,4 \\
\hline 28 & 220 & 540 & 31,8 & 80,4669 & 11,3 \\
\hline 29 & 208 & 600 & 39,1 & 44,0586 & 19 \\
\hline 30 & 360 & 420 & 29,99 & 85,5753 & 20,18 \\
\hline 31 & 440 & 230 & 31,5 & 123,061 & 27 \\
\hline 32 & 370 & 310 & 53,6 & 115,137 & 27,14 \\
\hline 33 & 430 & 170 & 52,3 & 57,8 & 14 \\
\hline 34 & 190 & 736 & 26,4 & 105,218 & 25,6 \\
\hline 35 & 210 & 774 & 22 & 130,818 & 15,52 \\
\hline 36 & 227 & 754 & 40,2 & 105,286 & 17 \\
\hline 37 & 330 & 475 & 57,9 & 37,8927 & 31,3 \\
\hline 38 & 580 & 280 & 32,8 & 98,6984 & 23,18 \\
\hline 39 & 21 & 36 & 4 & 1,6 & - \\
\hline 40 & 23 & 58 & 7,4 & 0,4 & - \\
\hline 41 & 210 & 140 & 7 & 11,9739 & 2,24 \\
\hline 42 & 230 & 540 & 29,6 & 24,7321 & 15,3 \\
\hline 43 & 390 & 446 & 38,07 & 164,646 & 16,6 \\
\hline 44 & 284 & 614 & 32,7 & 67,8086 & 19 \\
\hline 45 & 294 & 684 & 38,3 & 59,9942 & 18,9 \\
\hline 46 & 313 & 641 & 46,5 & 103,146 & 20 \\
\hline 47 & 316 & 578 & 33,9 & 98,249 & 15,5 \\
\hline 48 & 580 & 280 & 32,8 & 98,6 & 23,1 \\
\hline 49 & 260 & 670 & 46,5 & 108,021 & 15,29 \\
\hline 50 & 152 & 680 & 16,4 & 130,858 & 21 \\
\hline 51 & 261,2 & 590 & 32,4 & 115,979 & 23,6 \\
\hline 52 & 270 & 550 & 45,1 & 122,022 & 17,46 \\
\hline 53 & 460 & 370 & 51,4 & 134,484 & 19,26 \\
\hline 54 & 370 & 420 & 27,9 & 117,234 & 11,96 \\
\hline
\end{tabular}

Fonte: Os atributos físicos e químicos apresentados nesta tabela foram obtidos por Almeida et al. ${ }^{25}$ Correa ${ }^{26}$ Almeida et al. $;{ }^{27}$ Paes Sobrinho et al. $;{ }^{28}$ Bringhenti et al. ${ }^{29}$ Costa et al.,${ }^{30}$ Ferreira $;{ }^{31}$ Lunardi Neto e Almeida; ${ }^{32}$ Teske et al. ${ }^{33}$
Tabela 4. Teores recuperados e certificados de vanádio, molibdênio e antimônio para amostra referência SRM 2709 e Limites de Detecção e Quantificação.

\begin{tabular}{ccccccc}
\hline \multirow{2}{*}{ Elemento } & $\begin{array}{c}\text { Teor Recu- } \\
\text { perado }^{\mathrm{a}}\end{array}$ & $\begin{array}{c}\text { Teor } \\
\text { Certificado }^{\mathrm{b}}\end{array}$ & $\begin{array}{c}\text { Teor } \\
\text { Extraível }^{\mathrm{c}}\end{array}$ & $\begin{array}{c}\text { Recupera- } \\
\text { ção }^{\mathrm{d}}\end{array}$ & LD & LQ \\
\cline { 2 - 7 } & $---------------\mathrm{mg} \mathrm{kg}^{-1}-------------$ & $\%$ & $-----\mathrm{mg} \mathrm{kg}^{-1}$------ \\
\hline $\mathrm{V}$ & $64 \pm 8$ & 110 & $43-71$ & $58 \pm 7$ & 0,011 & 0,033 \\
$\mathrm{Mo}$ & $2,35 \pm 0,47$ & - & - & - & 0,026 & 0,078 \\
$\mathrm{Sb}$ & $1,29 \pm 0,15$ & 1,55 & $1,2-1,5$ & $83 \pm 6$ & 0,060 & 0,180 \\
\hline
\end{tabular}

${ }^{a}$ Teores médios e desvio padrão obtidos após digestão e leitura da amostra de solo refe-

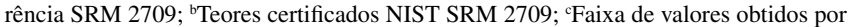
laboratórios utilizando uma metodologia de digestão "pseudo-total" da amostra referência

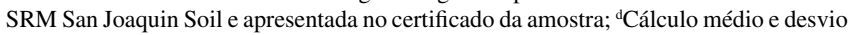
padrão da porcentagem de recuperação da amostra referência, obtido pela equação: \%recuperação $=($ Teor recuperado/ Teor certificado $) 100(1)$; - Teor não certificado.

Tabela 5. Teores médios e desvios padrão de $\mathrm{V}$ para cada material de origem de solo, extraídos pelo método USEPA 3051 A, quantificados em ICP OES e agrupamento estatístico

\begin{tabular}{|c|c|c|c|}
\hline Grupos $^{\mathrm{a}}$ & Material de Origem & $\begin{array}{c}\text { Teores de } \mathrm{V}^{\mathrm{b}} \\
\left(\mathrm{mg} \mathrm{kg}^{-1}\right)\end{array}$ & Desvio padrão \\
\hline \multirow{2}{*}{ A } & Andesito Basalto & 572,24 & 12,15 \\
\hline & Basalto & 418,41 & 127,73 \\
\hline \multirow{2}{*}{ B } & Riodacito & 130,89 & 72,68 \\
\hline & Olivina Melitito & 127,72 & 7,29 \\
\hline \multirow{15}{*}{$\mathrm{C}$} & Siltito & 65,24 & 4,40 \\
\hline & Sienito Porfírico & 56,01 & 2,06 \\
\hline & Hornblendito & 48,99 & 3,59 \\
\hline & Siltito e Arenito & 45,08 & 9,43 \\
\hline & Migmatito & 40,23 & 18,77 \\
\hline & Argilito e Siltito & 38,04 & 1,85 \\
\hline & Fonolito Porfírico & 35,55 & 1,03 \\
\hline & Granito e Granulito & 34,39 & 0,32 \\
\hline & Granulito Máfico & 32,00 & 15,18 \\
\hline & Fonolito & 21,79 & 4,00 \\
\hline & Meta-arenito & 21,62 & 2,33 \\
\hline & Granito & 19,82 & 8,68 \\
\hline & Micaxisto & 16,29 & 0,85 \\
\hline & Arenito e Siltito & 14,25 & 3,92 \\
\hline & Sedimentos Arenosos & 7,38 & 3,86 \\
\hline
\end{tabular}

${ }^{a}$ Médias pertencentes ao mesmo grupo não diferem entre si pelo teste ScottKnott $(\mathrm{p}<0,05)$. ${ }^{\mathrm{b}} \mathrm{O}$ teor de $\mathrm{V}$ corresponde ao teor médio do elemento-traço vanádio em todos os solos analisados que contenham o material de origem apresentado.

dos resultados. ${ }^{42}$ Diante disso, correlacionou-se os elementos determinados com as variáveis argila, carbono orgânico, capacidade de troca catiônica e óxidos de ferro (Tabela 8).

A relação negativa entre molibdênio e o carbono orgânico pode indicar que o aumento do conteúdo de matéria orgânica nos solos estudados pode reduzir a concentração de molibdênio. ${ }^{7} \mathrm{~A}$ associação do molibdênio com a matéria orgânica não é bem compreendida, alguns autores afirmam que o Mo está fortemente ligado a matéria orgânica do solo, enquanto outros encontram baixos teores do elemento em solos orgânicos. ${ }^{47}$ Autores como Paye et al., Melo et al. e Almeida Junior ${ }^{42,43,45}$ não encontraram relação significativa entre matéria orgânica e molibdênio. Fernandes et al. ${ }^{7}$ encontraram relação significativa e positiva entre Mo e o carbono orgânico. 
Tabela 6. Teores médios e desvios padrão de Mo para cada material de origem de solo, extraídos pelo método USEPA 3051 A, quantificados em ICP OES e agrupamento estatístico.

\begin{tabular}{cccc}
\hline Grupos $^{\mathrm{a}}$ & Tratamentos & $\begin{array}{c}\text { Teores de Mo } \\
\left(\mathrm{mg} \mathrm{kg}^{-1}\right)\end{array}$ & Desvio Padrão \\
\hline \multirow{3}{*}{ A } & Fonolito Porfírico & 5,36 & 0,30 \\
& Arenito e Siltito & 3,57 & 0,55 \\
& Siltito e Arenito & 3,51 & 1,01 \\
& Granito & 3,30 & 1,06 \\
& Meta-Arenito & 3,13 & 0,38 \\
& Sedimentos Arenosos & 2,82 & 0,50 \\
Micaxisto & 2,71 & 0,29 \\
Granito e Granulito & 2,54 & 0,16 \\
\hline Andesito Basalto & 2,20 & 0,06 \\
B & 2,20 & 0,01 \\
& Argilito e Siltito & 1,67 & 0,84 \\
Riodacito & 1,65 & 0,72 \\
Basalto & 1,64 & 0,58 \\
& Granulito Máfico & 1,59 & 0,67 \\
Fonolito & 1,40 & 0,48 \\
& Migmatito & 1,37 & 0,11 \\
& Siltito & 1,19 & 0,14 \\
& Sienito Porfírico & 0,96 & 0,04 \\
Hornblendito & 0,94 & 0,03 \\
\hline
\end{tabular}

${ }^{a}$ Médias pertencentes ao mesmo grupo não diferem entre si pelo teste ScottKnott $(\mathrm{p}<0,05) .{ }^{\mathrm{b}} \mathrm{O}$ teor de Mo corresponde ao teor médio do elemento-traço molibdênio em todos os solos analisados que contenham o material de origem apresentado.

Tabela 7. Teores médios de Sb para cada material de origem de solo, extraídos pelo método USEPA 3051 A e quantificados em ICP OES HG

\begin{tabular}{lcc}
\hline Tratamentos & Teores de $\mathrm{Sb}^{\mathrm{a}}\left(\mathrm{mg} \mathrm{kg}^{-1}\right)$ & Desvio Padrão \\
\hline Granulito Máfico & 0,81 & 0,13 \\
Meta-Arenito & 0,80 & 0,01 \\
Basalto & 0,51 & 0,26 \\
Riodacito & 0,41 & 0,26 \\
Argilito e Siltito & 0,32 & 0,07 \\
Migmatito & 0,29 & - \\
Andesito Basalto & 0,26 & 0,02 \\
Sedimentos Arenosos & 0,20 & - \\
Arenito e Siltito & $<\mathrm{LQ}$ & - \\
Siltito e Arenito & $<\mathrm{LQ}$ & - \\
Fonolito & $<\mathrm{LQ}$ & - \\
Micaxisto & $<\mathrm{LQ}$ & - \\
Granito & $<\mathrm{LQ}$ & - \\
Granito e Granulito & $<\mathrm{LQ}$ & - \\
Fonolito Porfirítico & $<\mathrm{LQ}$ & - \\
\hline
\end{tabular}

${ }^{\mathrm{a}} \mathrm{O}$ teor de $\mathrm{Sb}$ corresponde ao teor médio do elemento-traço antimônio em todos os solos analisados que contenham o material de origem apresentado. ${ }^{b} \mathrm{LQ}=0,18 \mathrm{mg} \mathrm{kg}^{-1}$.

A relação negativa entre Mo e $\mathrm{V}$ pode indicar que em solos com maior teor de um elemento, há menor teor de outro, o que pode ser explicado pela diferença na composição do material de origem dos solos.

O molibdênio normalmente se apresenta nos solos na forma de ânions $\left(\mathrm{MoO}_{4}{ }^{2-} \text { e } \mathrm{HMoO}_{4}\right)^{24}$ e a relação negativa com a CTC pode ocorrer pela maior disponibilidade de Mo na solução do solo e possível lixiviação ou porque os solos com maior CTC são os originados de
Tabela 8. Coeficientes de correlação linear de Pearson entre os teores de Mo, $\mathrm{V}, \mathrm{Sb}$ e os atributos do solo

\begin{tabular}{cccc}
\hline & Mo & $\mathrm{V}$ & $\mathrm{Sb}$ \\
\hline Mo & 1,00 & & \\
$\mathrm{~V}$ & $-0,31$ & 1,00 & \\
$\mathrm{Sb}$ & $\mathrm{NS}$ & 0,49 & 1,00 \\
Argila & $\mathrm{NS}$ & 0,35 & $\mathrm{NS}$ \\
Silte & $\mathrm{NS}$ & 0,39 & 0,33 \\
$\mathrm{CO}$ & $-0,54$ & 0,45 & 0,39 \\
$\mathrm{CTC}$ & $-0,41$ & 0,43 & $\mathrm{NS}$ \\
Fe & $-0,32$ & 0,94 & 0,46 \\
\hline NS - Não significativo & & &
\end{tabular}

basalto e riodacito, que contêm naturalmente menor quantidade do elemento que os de granito, que apresentaram menor CTC.

A fração argila possui capacidade de adsorver cátions como o vanádio devido sua maior área superficial específica e carga negativa. ${ }^{41} \mathrm{~A}$ adsorção do elemento na argila reduz a sua lixiviação. ${ }^{38}$ A correlação encontrada entre silte e vanádio e silte e antimônio provavelmente ocorre pela presença de minerais de argila e óxidos de Fe e Mn associados, que formam agregados do tamanho de silte. ${ }^{41}$

A CTC apresentou correlação positiva com o vanádio, demonstrando a importância deste parâmetro na retenção do elemento, que está presente predominantemente na forma de cátion, no solo. ${ }^{41}$

Normalmente, o vanádio forma complexos orgânicos de baixa reatividade com a matéria orgânica, inclusive a ligação covalente do $\mathrm{VO}^{2+}$ com matéria orgânica é muito forte, ${ }^{48}$ explicando a correlação positiva entre $\mathrm{V}$ e carbono orgânico.

A matéria orgânica, devido aos seus grupos funcionais, é importante na retenção e consequente redução da mobilidade de Sb no solo, ${ }^{19}$ através da adsorção ou formação de complexos com o elemento. ${ }^{49} \mathrm{O} \mathrm{Sb}$ tende se ligar em sítios orgânicos disponíveis, além de poder ser fortemente adsorvido em óxidos e hidróxidos de ferro. ${ }^{49}$

Características como raio iônico e estados de oxidação semelhantes favorecem a correlação entre elementos-traço. ${ }^{7} \mathrm{~A}$ substituição isomórfica de $\mathrm{Fe}^{3+}(0,067 \mathrm{~nm})$ por $\mathrm{V}^{3+}(0,065 \mathrm{~nm})$, $\mathrm{Sb}^{3+}(0,076 \mathrm{~nm})$, na estrutura dos óxidos Fe é favorecida devido à proximidade do raio iônico entre ambos. ${ }^{38}$

Óxidos, oxi-hidróxidos e hidróxidos de Fe desempenham um papel muito importante na adsorção de elementos-traço, através da incorporação, na sua superfície ou estrutura, por adsorção específica. ${ }^{19}$

A sorção de vanadato $\left(\mathrm{V}^{5+}\right)$ em óxidos de ferro $(3+)$ é forte e envolve a formação de complexos de esfera interna, embora o vanádio 5+ ocorra predominantemente em solos após sua adição de forma antrópica, o que não prevalece neste trabalho. ${ }^{50}$

Apesar de mais de um parâmetro avaliado apresentar correlação positiva com $\mathrm{V}$ e $\mathrm{Sb}$ e, portanto, influenciarem na sua presença e retenção em solos sem contaminação, aparentemente a presença de óxidos de ferro é o fator que mais contribui com a sua concentração em solos, bem como o material de origem, principalmente para o vanádio.

\section{CONCLUSÕES}

Os diferentes materiais de origem dos solos interferem fortemente na presença de elementos-traço nos solos, sendo os maiores teores de vanádio encontrados em solos com origem máfica. Já os mais elevados teores de molibdênio foram encontrados em outros tipos de solo, mais precisamente nos originados de fonolito porfírio, granito, micaxisto e rochas sedimentares.

Teores de V, Mo e Sb encontrados em solos de Santa Catarina se diferiram dos teores encontrados em solos de outras regiões do 
Brasil. Em geral, as concentrações de V e Mo foram maiores em SC.

Teores de silte, carbono orgânico, capacidade de troca catiônica e óxidos de ferro estão positivamente correlacionados com os elementos vanádio e antimônio em solos de Santa Catarina.

A determinação de teores de vanádio, antimônio e molibdênio em solos não contaminados é essencial para futuras ações de monitoramento dos elementos em solos do estado, auxiliando assim na identificação de áreas contaminadas, demonstrando se haverá a necessidade de adoção de práticas preventivas ou mitigadoras com a identificação e monitoramento de áreas contaminadas.

\section{AGRADECIMENTOS}

Os autores agradecem à Universidade do Estado de Santa Catarina (UDESC), à Coordenação de Aperfeiçoamento de Pessoal de Nível Superior (CAPES) e ao Programa de Apoio à Pesquisa (PAP) da Fundação de Amparo à Pesquisa e Inovação do Estado de Santa Catarina (FAPESC) / UDESC pelo apoio financeiro. Agradecem ainda ao professor J. A. de Almeida e seus orientados pela cessão de amostras de solo por eles coletadas.

\section{REFERÊNCIAS}

1. Almeida Júnior, A. B.; Tese de Doutorado, Universidade Federal Rural de Pernambuco, Brasil, 2014.

2. Biondi, C. M.; Tese de Doutorado, Universidade Federal Rural de Pernambuco, Brasil, 2010

3. Alloway, B. J.; Em Heavy metals in soils; Alloway, B. J., ed.; Chapman \& Hall: Great Britain, 1995; cap. 3.

4. Guagliardi, I.; Cicchella, D.; De Rosa, R.; Ricca, N.; Buttafuoco, G.; J. Geochem. Explor. 2018, 184, 358.

5. Rebêlo, A.; Monteiro, M.; Ferreira, S.; Ríos-Villamizar, E.; Quesada, C.; Duvoisin Junior, S.; Quim. Nova 2020, 43, 534.

6. Huang, Y.; Chen, Q.; Deng, M.; Japenga, J.; Li, T.; Yang, X.; He, Z.; J. Environ. Manage. 2018, 207, 159.

7. Fernandes, A. R.; Souza, E. S. de; de Souza Braz, A. M.; Birani, S. M.; Alleoni, L. R. F.; J. Geochem. Explor. 2018, 190, 453.

8. Conama; Resolução $n^{\circ} 420$, de 28 de dezembro de 2009, Brasil, 2009.

9. Rice, K.; Environ. Sci. Technol. 1999, 33, 2499.

10. Campos, M. L.; Guilherme, L. R. G.; Melo, J. J. G. de S. e M.; Curi, N.; Araújo, A. S. A.; Miquelluti, D. J.; Lopes, C.; Spiazzi, F. R.; Rev. Bras. Ciênc. Solo 2013, 37, 281.

11. Hugen, C.; Dissertação de Mestrado, Universidade do Estado de Santa Catarina, Brasil, 2010.

12. Hugen, C.; Miquelluti, D. J.; Campos, M. L.; Almeida, J. A. De; Ferreira, É. R. N. C.; Pozzan, M.; Rev. Bras. Eng. Agríc. Ambient. 2013 , 17,622 .

13. Souza, L. C. de; Tese de Doutorado, Universidade do Estado de Santa Catarina, Brasil, 2015.

14. Suppi, I. M.; Campos, M. L.; Miquelluti, D. J.; Bueno, D. K.; Revista de Ciências Agroveterinárias 2018, 17, 579.

15. Scheibe, L.; Geosul 1986, 1, 7.

16. Shaheen, S. M.; Alessi, D. S.; Tack, F. M. G.; Sik, Y.; Kim, K.; Petter, J.; Sparks, D. L.; Rinklebe, J.; Adv. Colloid Interface Sci. 2019, 265, 1.

17. Yang, J.; Teng, Y.; Wu, J.; Chen, H.; Wang, G.; Song, L.; Yue, W.; Zuo, R.; Zhai, Y.; Chemosphere 2017, 171, 635.

18. Multani, R. S.; Feldmann, T.; Demopoulos, G. P.; Hydrometallurgy 2016, 164, 141.

19. Herath, I.; Vithanage, M.; Bundschuh, J.; Environ. Pollut. 2017, 223, 545.

20. Földi, C.; Sauermann, S.; Dohrmann, R.; Mansfeldt, T.; Environ. Pollut. 2018, 237, 704.
21. ATSDR; Toxicological Profile for Antimony and Compounds, 2019.

22. Greaney, A. T.; Rudnick, R. L.; Gaschnig, R. M.; Whalen, J. B.; Luais, B.; Clemens, J. D.; Geochim. Cosmochim. Acta 2018, 238, 36.

23. ATSDR; Toxicological Profile for Molybdenum, 2020.

24. Kabata-pendias, A.; Mukherjee, A. B.; Trace Elements from Soil to Human; 1st ed., Springer-Verlag: Berlin, 2007.

25. Almeida, J. A.; Torrent, J.; Barron, V. .; Rev. Bras. Ciênc. Solo 2003, 27, 985.

26. Correa, J.; Dissertação de Mestrado, Universidade do Estado de Santa Catarina, Brasil, 2003.

27. de Almeida, J. A.; Cararo, D. C.; Uberti, A. A. A.; Rev. Bras. Ciênc. Solo 2009, 33, 405 .

28. Paes Sobrinho, J. B.; Almeida, J. A.; Erhart, J.; Revista de Ciências Agroveterinárias 2009, 8, 9 .

29. Bringhenti, I.; Almeida, J. A. de; Hofer, A.; Rev. Bras. Ciênc. Solo 2012, $36,1057$.

30. Costa, A. da; Albuquerque, J. A.; de Almeida, J. A.; da Costa, A.; Luciano, R. V.; Rev. Bras. Ciênc. Solo 2013, 37, 889.

31. Ferreira, É. R. N. C.; Tese de Doutorado, Universidade do Estado de Santa Catarina, Brasil, 2013.

32. Lunardi Neto, A.; de Almeida, J. A.; Revista de Ciências Agroveterinárias 2013, 12, 282.

33. Teske, R.; Almeida, J. A. De; Hoffer, A.; Lunardi Neto, A.; Revista de Ciências Agroveterinárias 2013, 12, 175.

34. USEPA; Method 3051A: Microwave assisted acid digestion of sediments, sludges, soils, and oils, 2007.

35. R Development Core Team; R: A Language and Environment for Statistical Computing; R Foundation for Statistical Computing, Austria, 2016.

36. Apha; Standard methods for the examination of water and wastewater; $22^{\text {nd }}$ ed., American Public Health Association: New York, 2012.

37. Evans, L. J.; Barabash, S. J.; Em Trace Elements in Soils; Hooda, P.S., ed.; Wiley: Chichester, 2010, cap. 22.

38. Bocardi, J. M. B.; Pletsch, A. L.; Melo, V. F.; Quinaia, S. P.; J. Geochem. Explor. 2020, 217, 106591.

39. Huang, J.; Huang, F.; Evans, L.; Glasauer, S.; Chem. Geol. 2015, 417, 68.

40. Wu, W.; Qu, S.; Nel, W.; Ji, J.; Chemosphere 2021, 262, 127897.

41. Preston, W.; do Nascimento, C. W. A.; Biondi, C. M.; de Souza Junior, V. S.; Da Silva, W. R.; Ferreira, H. A.; Rev. Bras. Ciênc. Solo 2014, 38, 1028.

42. Paye, H. de S.; Mello, J. W. V. de; Abrahão, W. A. P.; Fernandes Filho, E. I.; Dias, L. C. P.; Castro, M. L. O.; Melo, S. B. de; França, M. M.; Rev. Bras. Ciênc. Solo 2010, 34, 2041.

43. Melo, V. F.; Buschle, B.; Souza, L. C. P.; Bonfleur, E. J.; J. Geochem. Explor. 2017, 181, 138.

44. de Camargo, W. G. R.; Tese de Doutorado, Universidade de São Paulo, Brasil, 1945.

45. de Almeida Júnior, A. B.; Nascimento, C. W. A. do; Biondi, C. M.; Souza, A. P. de; Barros, F. M. do R.; Rev. Bras. Ciênc. Solo 2016, 40, 1.

46. Fabricio Neta, A. de B.; do Nascimento, C. W. A.; Biondi, C. M.; van Straaten, P.; Bittar, S. M. B.; Environ. Geochem. Health 2018, 40, 163.

47. de Camargo, O. A. In Micronutrientes na Agricultura; Ferreira, M. E., Cruz, M. C. P., eds.; POTAFOS/CNPq: Piracicaba, 2006, pp. 243-272.

48. Reijonen, I.; Metzler, M.; Hartikainen, H.; Environ. Pollut. 2016, 210, 371.

49. Zhu, Y. M.; Yang, J. G.; Wang, L. Z.; Lin, Z. T.; Dai, J. X.; Wang, R. J.; Yu, Y. S.; Liu, H.; Rensing, C.; Feng, R. W.; Sci. Total Environ. 2020, $738,140232$.

50. Larsson, M. A.; Hadialhejazi, G.; Gustafsson, J. P.; Chemosphere 2017, 168,925 . 